\title{
OBITUARY FOR Dr. VLADIMIR K. KHARCHENKO
}

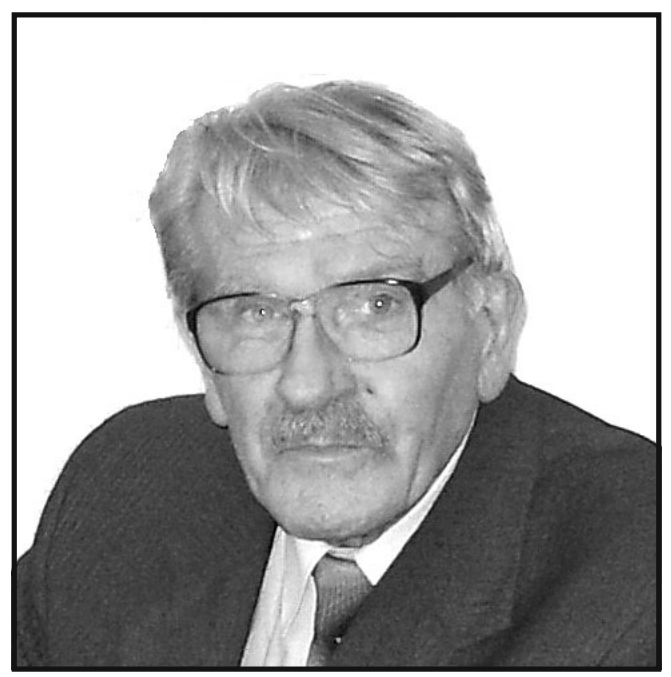

Vladimir K. Kharchenko, a well-known scientist in the field of high-temperature strength of structural materials, Ph.D., senior research worker, associate editor of the Strength of Materials Journal passed away on January 25, 2013.

Vladimir K. Kharchenko was born in Odessa on December 15, 1930. In 1952 he graduated from Kiev Polytechnical Institute by a speciality of mechanical engineer. In 1952-1960 he worked in several industrial plants of Kiev. Since 1960 his scientific activities were closely connected with institutions of National Academy of Sciences of Ukraine. He worked as a leading engineer, then chief engineer at the Institute of Metal Ceramics and Special Alloys, as a chief engineer at the Institute for Materials Science Problems (1960-1966), as a senior research worker at Pisarenko Institute of Problems of Strength (1966-1973), from 1973 to 1990 he was the Head of the Department, Special Design\&Technology Bureau of this Institute. From the very outset of the Strength of Materials Journal foundation (1969) Vladimir K. Kharchenko was an executive secretary and then an associate editor (1991-2013).

His research and development activities were aimed at the advancement of the research line in mechanics, studying high-temperature strength of materials and structural elements. He published over 100 scientific works, including 3 monographs, and obtained 7 patents. His major studies are devoted to investigation of short-term strength of refractory materials at high temperatures. V. K. Kharchenko and his co-workers developed new unique procedures, devices, and units for high-temperature mechanical tests. He performed complex strength tests of refractory materials (including tungsten-copper pseudoalloys) over a temperature range of 290-3300 K under short-term static and low-cycle loadings, in instantaneous creep, and at a multiaxial stress state with regard to the thermal treatment of materials, technology, welding conditions, and other factors for their employment at spacerocket engineering objects in leading organizations of the USSR and Ukraine.

V. K. Kharchenko was a member of the Section of physicochemical fundamentals for the production of powder and composite materials of the Scientific Council, Academy of Sciences of the USSR, for the complex program Physicochemical Fundamentals of Metallurgical Processes. He was awarded with M. K. Yangel Prize of Academy of Sciences of UkrSSR for the series of studies High-Temperature Strength of Refractory and Composite Materials and Their Application in Space Apparatus (1990) and with the State Prize of Ukraine in the field of science and technology for the study Strength and Performance of Materials and Structural Elements of SpaceRocket Engineering (1994). His name was put down in Encyclopedia of Astronautics.

V. K. Kharchenko was a prominent scientist, skilled editor, a man of outstanding personality with deep knowledge of life. He will be sadly missed by those who knew and came into line with him. 